\title{
PEMBINAAN REMAJA ANTI KEKERASAN MELALUI KEGIATAN MaGoSchool (Mahasiswa Go To School) DI KOTA BOGOR
}

\author{
Fajar Maulidi Rahmani, Intan Rahma Utami, Halimah Tussakdiah, Rikotul Kolbiyah. \\ fajarmaulidi48@gmail.com \\ Mahasiswa Fakultas Agama Islam
}

\begin{abstract}
ABSTRAK
Judul PKM-M ini adalah Pembinaan remaja anti kekerasan melalui kegiatan MaGoSchool (mahasiswa go to school) di Kota Bogor. Latar belakang masalah untuk mengadakan kegiatan pengabdian ini berawal dari keprihatinan kami terhadap kasus tawuran atau kekerasan antar pelajar yang semakin meningkat. Dan maraknya aksi tawuran antar pelajar khususnya di Bogor. Selain itu, masih kurangnya perhatian terhadap perkembangan remaja untuk mengapresiasikan diri. Sasaran dari kegiatan ini adalah para pelajar dari beberapa SMK swasta di kota Bogor yang sangat dikenal masyarakat sering melakukan aksi tawuran. Untuk mengatasi masalah tersebut kami bekerjasama dengan Himpunan Mahasiswa (HIMA) PGMI untuk mengadakan seminar remaja anti kekerasan dan perombaan, serta games motivasi. Kegiatan ini juga melibatkan pihak sekolah serta pihak yang berwajib sebagai narasumber. Luaran dari kegiatan PKM-M ini berupa buku pendidikan remaja, dan artikel tentang remaja serta seminar.
\end{abstract}

Kata Kunci: Remaja, Anti Kekerasan, MaGoSchool.

\section{PENDAHULUAN}

\section{Latar Belakang}

Sentimen antar sekolah yang kemudian berlanjut pada aksi tawuran antar pelajar tak hanya terjadi di tingkat siswa SMP maupun SMA. Bahkan, saat ini sentimen antarsekolah juga terjadi di tingkat pelajar SD. Karena itu, kemampuan tenaga pendidik untuk menanamkan budaya ramah tamah serta keterbukaan terhadap siswa kepada gurunya perlu ditingkatkan.

Perkelahian antarpelajar kerap kali terjadi bahkan memakan korban jiwa. Terakhir, perkelahian antarpelajar terjadi antara siswa SMP di Rumpin, Kabupaten Bogor. Akibatnya salah satu korban tewas karena sabetan celurit. Sedangkan di Banjaran, Kabupaten Bandung, Jawa Barat juga terjadi perkelahian antarsiswa SD yang juga menyebabkan satu anak meninggal dunia. Berikut ini daftar kasus aksi tawuran yang terjadi sepanjang tahun 2017 di Jabodetabek:



Daftar Aksi Tawuran (kekeran antar pelajar Jabodetabek tahun 2017)

Sumber: Krimonologi.id

Komisioner KPAI Bidang Pendidikan Retno Listyarti (2017) mengatakan, lemahnya pengawasan baik oleh orang tua, pengajar di sekolah, 
maupun masyarakat menyebabkan seringnya terjadi perkelahian antarpelajar. Menurut dia, perkelahian antarpelajar biasanya terjadi di luar sekolah serta di luar jam pelajaran sehingga membutuhkan pengawasan orang tua dan masyarakat sekitar. "Peristiwa tarung gladiator ini terjadi karena lemahnya pengawasan orang dewasa, baik di sekolah, di rumah, maupun di masyarakat," kata Retno saat dihubungi Republika.co.id, Ahad (26/11).

Orang tua seharusnya memiliki kepekaan terhadap anak-anak mereka jika akan merencanakan perkelahian maupun tawuran. Sebab, perkelahian antarsiswa, lanjut dia, biasanya telah direncanakan terlebih dahulu. Selain itu, masyarakat juga dimintanya untuk berperan turut membubarkan aksi tawuran maupun perkelahian pelajar. Biasanya, perkelahian terjadi di tempat umum yang melibatkan beberapa pelajar.Sehingga, diharapkan masyarakat peka dan dapat segera menghubungi aparat hukum untuk mencegah terjadi perkelahian. Perkelahian antarsiswa juga dapat melibatkan siswa senior ataupun alumni. Karena itu, guru di sekolah pun seharusnya juga memiliki kepekaan terhadap para anak didiknya yang memiliki potensi untuk berkelahi.

Pengamat Pendidikan Doni

Koesoema (2017) menilai kurangnya penanaman karakter moral terhadap siswa untuk bersikap ramah menjadi salah satu penyebab pelajar sering kali melakukan perkelahian maupun tawuran. Sikap tersebut kurang ditanamkan oleh para tenaga pengajar di sekolah.

Berkaitan dengan masalah ini, dalam pandangan psikologi, setiap perilaku merupakan interaksi antara kecenderungan di dalam diri individu (sering disebut kepribadian, walau tidak selalu tepat) dan kondisi eksternal. Begitu pula dalam hal perkelahian pelajar. Bila dijabarkan, terdapat sedikitnya 4 faktor psikologis mengapa seorang remaja terlibat perkelahian pelajar.

1. Faktor internal. Remaja yang terlibat perkelahian biasanya kurang mampu melakukan adaptasi pada situasi lingkungan yang kompleks. Kompleks di sini berarti adanya keanekaragaman pandangan, budaya, tingkat ekonomi, dan semua rangsang dari lingkungan yang makin lama makin beragam dan banyak. Situasi ini biasanya menimbulkan tekanan pada setiap orang. Tapi pada remaja yang terlibat perkelahian, mereka kurang mampu untuk mengatasi, apalagi memanfaatkan situasi itu untuk pengembangan dirinya. Mereka biasanya mudah putus asa, cepat melarikan diri dari masalah, menyalahkan orang / pihak lain pada setiap masalahnya, dan memilih menggunakan cara tersingkat untuk memecahkan masalah. Pada remaja yang sering berkelahi, ditemukan bahwa mereka mengalami konflik batin, mudah frustrasi, memiliki emosi yang labil, tidak peka terhadap perasaan orang lain, dan memiliki perasaan rendah diri yang kuat. Mereka biasanya sangat membutuhkan pengakuan.

2. Faktor keluarga. Rumah tangga yang dipenuhi kekerasan (entah antar orang tua atau pada anaknya) jelas berdampak pada anak. Anak, ketika meningkat remaja, belajar bahwa kekerasan adalah bagian dari dirinya, sehingga adalah hal yang wajar kalau ia melakukan kekerasan pula. Sebaliknya, orang tua yang terlalu melindungi anaknya, ketika remaja akan tumbuh sebagai individu yang tidak mandiri dan tidak berani mengembangkan identitasnya yang unik. Begitu bergabung dengan temantemannya, ia akan menyerahkan dirnya secara total terhadap kelompoknya sebagai bagian dari identitas yang dibangunnya.

3. Faktor sekolah. Sekolah pertamatama bukan dipandang sebagai lembaga yang harus mendidik siswanya menjadi sesuatu. Tetapi sekolah terlebih dahulu harus dinilai dari kualitas pengajarannya. Karena itu, lingkungan sekolah yang tidak merangsang siswanya untuk belajar (misalnya suasana kelas yang monoton, peraturan yang tidak relevan dengan pengajaran, tidak adanya fasilitas praktikum, dsb.) akan menyebabkan siswa 
lebih senang melakukan kegiatan di luar sekolah bersama teman-temannya. Baru setelah itu masalah pendidikan, di mana guru jelas memainkan peranan paling penting. Sayangnya guru lebih berperan sebagai penghukum dan pelaksana aturan, serta sebagai tokoh otoriter yang sebenarnya juga menggunakan cara kekerasan (walau dalam bentuk berbeda) dalam "mendidik" siswanya.

4. Faktor lingkungan. Lingkungan di antara rumah dan sekolah yang sehari-hari remaja alami, juga membawa dampak terhadap munculnya perkelahian. Misalnya lingkungan rumah yang sempit dan kumuh, dan anggota lingkungan yang berperilaku buruk (misalnya narkoba). Begitu pula sarana transportasi umum yang sering menomor-sekiankan pelajar. Juga lingkungan kota (bisa negara) yang penuh kekerasan. Semuanya itu dapat merangsang remaja untuk belajar sesuatu dari lingkungannya, dan kemudian reaksi emosional yang berkembang mendukung untuk munculnya perilaku berkelahi.

Maka dari itu salah satu upaya yang dapat dilakukan dalam masalah ini adalah mengadakan kegiatan pembinaan secara rutin. Selain pihak sekolah dan keluarga, masyarakat juga harus turut andil. Sebagai mahasiswa kami juga turut perihatin dan merasa terpanggil untuk melakukan kegiatan positif dalam menangani masalah ini. Salah satunya yaitu melalui aksi langsung mahasiswa dalam PKM-M yaitu MaGoSchool (Mahasiswa Go to School) melalui kegiatan Seminar Remaja Anti Kekerasan dan Games Motivasi. Selain itu akan membagikan Buku Pendidikan Remaja serta menerbitkan artikel ilmiah di jurnal atau seminar nasional.

\section{Potret, Profil, Dan Kondisi Khalayak Sasaran \\ Kami akan mengadakan}

MaGoSchool ke salah satu Yayasan yang terdiri dari beberapa SMK Swasta Tri Dharma (SMK TD 1,2,3 dan 4) yang berlokasi di Kota Bogor. Alasan memilih sekolah ini adalah karena sekolah ini meresahkan masyarakat karena dikenal sering melakukan aksi tawuran atau kekerasan antar pelajar. Padahal usia mereka masih tergolong remaja.

\section{Kondisi Dan Potensi Wilayah}

Potensinya akan cukup bagus mengingat bagaimana di sekolah tersebut jarang diberikan wawasan tentang pergaulan remaja dimana pada usia remaja seringkali terjadi hal-hal yang tidak diinginkan. Dari segi sosial ekonomi di sekolah ini rata-rata dari kelas menengah kebawah yang diperkiraan kurangnya fasilitas pendukung baik dari sekolah maupun keluarga untuk hal-hal yang membuat para remaja ini melakukan kegiatan yang positif. Dari segi lokasi SMK ini sangat dekat dengan Kampus Ibn Khaldun Bogor dan letaknya strategis dekat jalan raya.

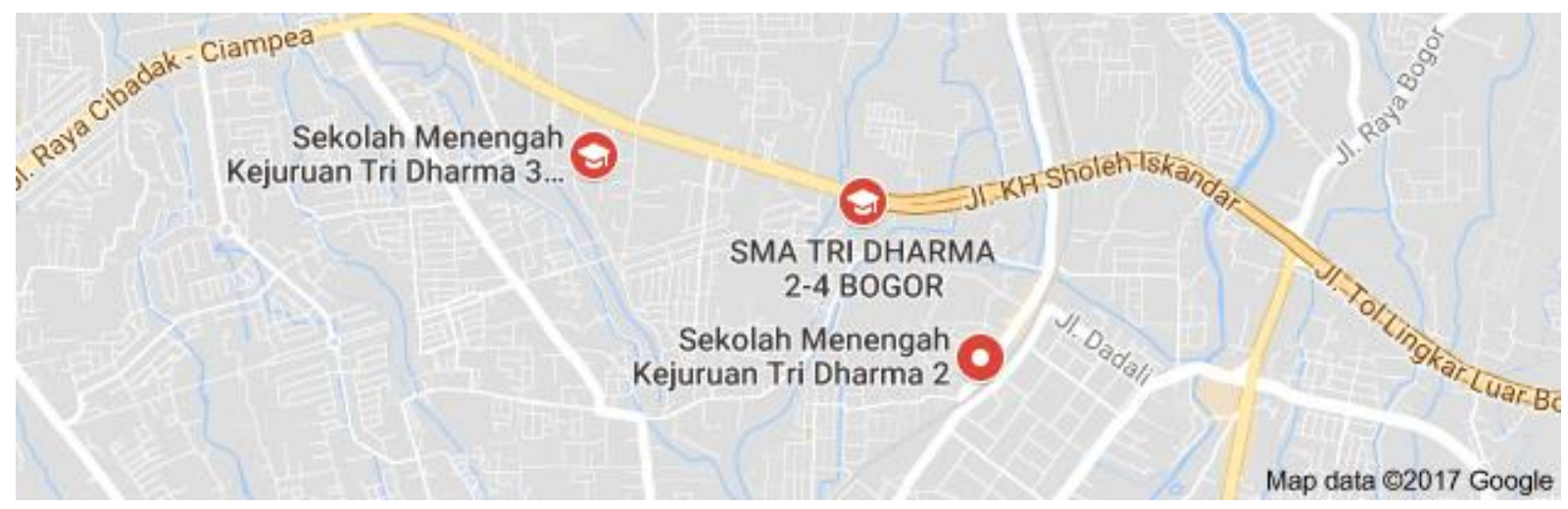

Peta Lokasi SMK Tri Dharma (TD) Bogor 




Lokasi SMK TD 1,2 3 dan 4 Bogor
SMK TRI DHARMA 1 KOTA BOGOR. Jalan Kebon Pedes No.46 Bogor jurusan otomotif. SMK Tri Dharma 2 Bogor Di dirikan di atas luas tanah +2300 m2 oleh YAYASAN TRI DHARMA BOGOR pada tahun 1993 dan selesai pada tahun 1995 yang berlokasi di J1. Raya Kebon Pedes No. 25 Bogor yang berjumlah 2 lokal (tingkat), itu merupakan pertama kali YAYASAN TRI DHARMA BOGOR mendirikan Sekolah Menengah Kejuruan (SMK/SMEA) yang termasuk dalam kelompok Bisnis Dan Manajemen setelah kelompok Teknologi dan Industri (STM). Jurusan (Program Keahlian) yang di pertama kali di buka adalah Jurusan Administrasi Perkantoran (SEKRETARIS) dan Manajemen Bisnis (PENJUALAN), namun dikarenakan jumlah siswa dari tahun ke tahun terus bertambah maka pada tahun 1997 SMK Tri Dharma 2 Bogor kembali mendirikan gedung di atas luas tanah + $5000 \mathrm{~m} 2$ sebanyak 3 lokal (tingkat) yang berlokasi di Jl. Raya K.H. Sholeh Iskandar No. 5 (Jl. Baru Kedung Badak) Bogor dan selesai pada tahun 1999 bersamaan dengan dibukanya Program Keahlian/Jurusan AKUNTANSI untuk memenuhi tuntutan Dunia Kerja / Dunia Usaha. Pada tahun 2001 YAYASAN TRI DHARMA BOGOR kembali membuka Sekolah Menengah Kejuruan (SMK) yaitu SMK Tri Dharma 4 Bogor untuk Program Keahlian / Jurusan : SEKRETARIS, PENJUALAN, AKUNTANSI dengan Kepala Sekolah Yang berbeda.

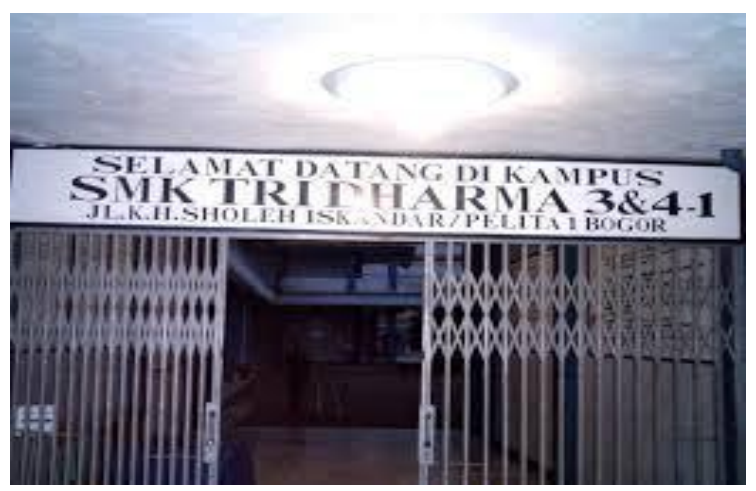

Kondisi masyarakat sasaran yang akan menerima kegiatan

Sekolah ramah anak menjadi impian bagi masyarakat. Kondisi masyarakat di tempat ini adalah banyak masyarakat yang mengharapkan kegiatan positif untuk mengurangi masalah pada remaja ini, dimana mereka sering melihat para siswa berkumpul di tempat-tempat dan seringkali memicu terjadinya tawuran, dan pasti akan memberikan nilai positif pada kegiatan ini. Namun pada dasarnya semua remaja pasti mempunyai keinginan untuk hidup lebih nyaman dan dengan kegiatan ini diharapkan banyak muncul ide-ide untuk mengurangi hal tidak baik tersebut.

Semoga dengan adanya kerjasama antar pihak sekolah dang tim PKM-M akan memberikan hal positif bagi sekolah. Sekolah tentunya mengharapkan ulurn tangan banyak pihak untuk mengatasi aksi kekeran antar pelajar ini. Semoga MaGoSchool bisa menjadi program pembinaan berkelanjutan.

\section{Permasalahan yang Dihadapi}

Sering terjadinya aksi tawuran (kekeran antar pelajar), hingga ada yang terluka bahkan meregang nyawa. Aksi tawuran ini teroganisir, mereka memiliki gank dan komunitas wadah berkumpul bahkan turun menurun di inisiasi alumni dan terus mencari generasi penerusnya yaitu para siswa baru. Permasalahan lainnya yaitu para remaja kurangnya tempat untuk mereka mengapresiasikan 
diri jadi para remaja mungkin lebih nyaman berkumpul bersama temantemannya dan itu menjadi salah satu penyebab akan adanya kekerasan terhadap seseorang. Disaat emosi tidak stabil disaat itulah orang akan melakukan apapun yang akan dilakukannya. Secara psikologis, perkelahian yang melibatkan pelajar usia remaja digolongkan sebagai salah satu bentuk kenakalan remaja (juvenile deliquency). Kenakalan remaja, dalam hal perkelahian, dapat digolongkan ke dalam 2 jenis delikuensi yaitu situasional dan sistematik. Pada delikuensi situasional, perkelahian terjadi karena adanya situasi yang "mengharuskan" mereka untuk berkelahi. Keharusan itu biasanya muncul akibat adanya kebutuhan untuk memecahkan masalah secara cepat. Sedangkan pada delikuensi sistematik, para remaja yang terlibat perkelahian itu berada di dalam suatu organisasi tertentu atau geng. Di sini ada aturan, norma dan kebiasaan tertentu yang harus diikuti angotanya, termasuk berkelahi. Sebagai anggota, mereka bangga kalau dapat

\section{METODE PELAKSANAAN}

\section{Tahap Persiapan Pelaksanaan}

Membuat kegiatan seminar di sekolah untuk memberikan wawasan kepada para siswa/i tentang kekerasan pada remaja. Mendatangi sekolah yang akan di tuju dengan meminta izin kepada pihak sekolah akan melaksanakan kegiatan MaGoSchool serta menghubungi narasumber. Tim juga akan menyiapakan perlengkapan yang dibutuhkan.

\section{Pelaksanaan}

Seminar akan di hadiri oleh kepolisian Kota Bogor yang bertindak sebagai narasumber. Dalam seminar melakukan apa yang diharapkan oleh kelompoknya. Jelas bahwa kondisi perkelahian pelajar ini merugikan banyak pihak. Paling tidak ada empat kategori dampak negatif dari perkelahian pelajar. Pertama, pelajar (dan keluarganya) yang terlibat perkelahian sendiri jelas mengalami dampak negatif pertama bila mengalami cedera atau bahkan tewas. Kedua, rusaknya fasilitas umum seperti bus, halte dan fasilitas lainnya, serta fasilitas pribadi seperti kaca toko dan kendaraan. Ketiga, terganggunya proses belajar di sekolah. Terakhir, mungkin adalah yang paling dikhawatirkan para pendidik, adalah berkurangnya penghargaan siswa terhadap toleransi, perdamaian dan nilai-nilai hidup orang lain. Para pelajar itu belajar bahwa kekerasan adalah cara yang paling efektif untuk memecahkan masalah mereka, dan karenanya memilih untuk melakukan apa saja agar tujuannya tercapai. Akibat yang terakhir ini jelas memiliki konsekuensi jangka panjang terhadap kelangsungan hidup bermasyarakat di Indonesia.

tersebut akan diadakan ice breaking berupa games yang akan membawa siswa lebih berperan aktif dalam seminar tersebut. Lalu siswa mengisi lembaran tentang apa tanggapan mereka terkait banyaknya kekerasan terhadap remaja, lalu membuat aktivitas rutin sebagai wadah positif untuk siswa seperti perlombaan antar siswa dan games motivasi.

\section{Evaluasi}

Mengevaluasi apakah cara tersebut dapat meredam emosi pada seorang remaja mungkin tidak cukup sekali untuk melakukan kegiatan tersebut dan membuka 
Mindsets siswa agar menjadi lebih baik kedepannya dan untuk keberhasilan hidup mereka juga kita perlu memberikan suatu wawasan yang baik dan berguna untuk mereka dengan orang yang handal dibidangnya.
Evaluasi kegiatan ini akan dilaksanakan secara komprehensif, merefleksi setiap kegiatan apakah berjalan dengan baik dan apa kendala atau hambatan serta tindak lanjut yang akan dilaksanakan.

\section{BIAYA DAN JADWAL KEGIATAN}

\begin{tabular}{|c|c|c|}
\hline No & Jenis Pengeluaran & Biaya (Rp) \\
\hline \multirow[t]{7}{*}{1.} & Peralatan Penunjang & \\
\hline & 1). Sewa kamera digital & Rp. 300.000 \\
\hline & 2). Sewa LCD dan layar & Rp. 250.000 \\
\hline & 3). Sewa ruang pelatihan & Rp. 450.000 \\
\hline & 4). Dana kebersihan ruang pelatihan & Rp. 250.000 \\
\hline & 5). Dana internet/ listrik & Rp. 250.000 \\
\hline & Total 1 & Rp. 1.500 .000 \\
\hline \multirow[t]{4}{*}{2.} & Bahan Habis Pakai & \\
\hline & $\begin{array}{l}\text { 1). ATK (Kertas, Buku Gambar Sketbook, } \\
\text { Pensil Warna, Pulpen, Penghapus,Papan } \\
\text { Belajar), Desain model Jurnal Lanskap dan } \\
\text { fotocopy materi }\end{array}$ & Rp. 3000.000 \\
\hline & 2). Konsumsi program kegiatan & Rp. 1.500 .000 \\
\hline & Total 2 & Rp. 4.500 .000 \\
\hline \multirow[t]{6}{*}{3.} & Perjalanan & \\
\hline & 1). Survey lokasi & Rp. 200.000 \\
\hline & 2). Transportasi pelatihan dan pemantuan & Rp. 300.000 \\
\hline & 3). Transportasi peserta & Rp. 500.000 \\
\hline & 4). Transportasi pendamping & Rp. 500.000 \\
\hline & Total 3 & Rp. 1.500 .000 \\
\hline \multirow[t]{5}{*}{4.} & Lain-lain : Administrasi, Seminar, Laporan, & \\
\hline & 1). Administrasi & Rp. $\quad 250.000$ \\
\hline & 2). Seminar & Rp. 1.500 .000 \\
\hline & 3). Laporan & RP. 250.000 \\
\hline & Total 4 & Rp. 2.000 .000 \\
\hline \multicolumn{2}{|c|}{ Jumlah } & Rp. 9.000 .000 \\
\hline
\end{tabular}




\begin{tabular}{|l|l|l|l|l|l|l|}
\hline \multirow{2}{*}{ No } & \multirow{2}{*}{ Jenis Kegiatan } & \multicolumn{5}{|c|}{ Bulan } \\
\cline { 3 - 7 } & & $\mathbf{l}$ & $\mathbf{2}$ & $\mathbf{3}$ & $\mathbf{4}$ & $\mathbf{5}$ \\
\hline 1 & $\begin{array}{l}\text { Persiapan perangkat } \\
\text { workshop }\end{array}$ & & & & & \\
\hline 2 & Workshop 1 & & & & & \\
\hline 3 & Workshop 2 & & & & & \\
\hline 4 & $\begin{array}{l}\text { Evaluasi dan } \\
\text { Laporan }\end{array}$ & & & & & \\
\hline 5 & $\begin{array}{l}\text { Publikasi/artikel } \\
\text { ilmiah/seminar }\end{array}$ & & & & & \\
\hline
\end{tabular}

\section{KESIMPULAN}

\section{Luaran yang diharapkan}

\begin{tabular}{|c|c|c|}
\hline No & Jenis Luaran & Keterangan (bentuk) \\
\hline 1. & Buku Pendidikan Remaja & Buku \\
\hline 2. & Kegiatan Remaja & $\begin{array}{c}\text { Seminar Anti Kekerasan, Games Motivasi, } \\
\text { Perlombaan antar siswa }\end{array}$ \\
\hline 3. & Publikasi Ilmiah & $\begin{array}{c}\text { Akan diterbitkan di Jurnal LPPM Univ. Ibn } \\
\text { Khaldun Bogor }\end{array}$ \\
\hline
\end{tabular}

\section{Manfaat Pengabdian}

1 Aksi nyata kepedulian mahasiswa terhadap remaja

2 Mengurangi aksi kekerasan (tawuran) pada remaja

3 Pembinaan bagi remaja untuk mencegah aksi tawuran

4 Membantu terciptanya lingkungan yang aman di Sekolah

5 Menumbuhkan sekolah yang Ramah Anak

6 Membentuk kepribadian remaja yang Positif dan kreatif 


\section{REFERENSI}

Data aksi Tawuran Jabodetabek kpai-lemahnya-pengawasanhttps://kriminologi.id/multimedia/inf ografik/infografik-aksi-tawuranpelajar-se-jabotabek-2017 sebabkan-perkelahian-pelajar

Kusuma.Doni.(2017)http://www.republika. co.id/berita/pendidikan/eduaction/17/

Listiyati,Retno.(2017).

http://www.republika.co.id/berita/nas 11/26/p00emq318-ini-penyebabsiswa-gampang-tawuran 